\title{
Sustainable natural consumption as a strategy for mitigating climate change in Colombia: understanding local conditions to match global issues
}

\author{
A. González Castaño, G. L. Penagos García \& S. Molina Escobar \\ Laboratorio de Estudios y Experimentación Técnica en Arquitectura \\ Facultad de Arquitectura Universidad Pontificia Bolivariana, Colombia
}

\begin{abstract}
According to the Intergovernmental Panel on Climate Change (IPCC) the building sector is responsible for $40 \%$ of greenhouse gas (GHG) emissions. Since most of the global electricity comes from fossil fuels, most of the GHG emissions from buildings are caused by the consumption of electric power during the operation phase. Hence energy efficiency in buildings has been identified as one of the main strategies for climate change mitigation. In Colombia, this strategy is part of the National Plan for Low Carbon Development. Although in this country $70 \%$ of electricity is produced from hydropower, a renewable source with low GHG emission factors.

On the other hand there is a high deficit of social housing and an accelerated process of urban growth in Colombia, where the building systems are characterized by a low level of industrialization, a high intensity of materials $(2.5$ ton $\left./ \mathrm{m}^{2}\right)$ and a substantial production of construction waste $\left(1.0 \mathrm{ton} / \mathrm{m}^{2}\right)$. By using emission factors for construction materials in Colombia, recently calculated by the United Nations Environmental Programme and the National Unidad de Planeación Mineroenergética, this study conducted at The Metropolitan Area of the Aburrá Valley shows that production of materials for the construction of new buildings produces 2.4 times more GHG emissions annually than the total electricity consumption of all existing buildings. There are no emission factors from construction activities and construction waste disposal specific to the Aburrá Valley, but these would evidently be directly related to the total weight of materials involved. Although electricity efficiency of buildings is an important
\end{abstract}


issue to urban sustainability in terms of economic costs, we conclude that a strategy oriented to reducing the intensity of materials in the construction sector would have an impact, not only larger but also probably more cost-effective, on reducing national GHG emissions.

Keywords: carbon footprint, sustainable materials, construction systems, emissions, life cycle.

\section{Introduction}

The largest urban population growth happens in developing countries located in Central Asia, Middle East, Southeast Asia, Africa and Latin America. This situation generates a complex problem in these regions, given the persistence of high levels of economic inequality and multidimensional poverty, characterized by poor access to water, sanitation, health services, education, employment and housing.

Metropolitan areas are densified in an accelerated manner, altering the hydrological cycle within the local climate as well ecological structures. As cities grow, they increase their demand for energy, water and raw materials, creating high levels of pollution emissions, discharges and solid waste.

Under these circumstances, the metropolitan area of the Aburrá Valley has, as a result of growth and increased building activity, a series of impacts that extend beyond the physical boundaries of the urban environment, to the regional level, such as air pollution from construction processes and materials manufacturing, soil degradation, scenery deterioration, loss of biodiversity, and scarcity and poor quality of water resources.

The purpose of the research is to evaluate by using emission factors for building materials in Colombia, the terms of carbon footprint generated by traditional construction systems in the metropolitan area of the Aburrá Valley and, from that, develop strategies for mitigation to ensure sustainable development of the construction and reduce the implications and impact on the environment.

\section{Conceptual framework}

The calculation of carbon footprint represents a methodology to measure the impact that making a product leaves on the planet - a count of emissions of carbon dioxide $\left(\mathrm{CO}_{2}\right)$, which are released into the atmosphere due to industrial processes necessary for its construction. This analysis covers all activities of the life cycle of a product, from procurement of raw materials to their management disposal as waste, allowing consumers to decide which products to purchase as pollution generated, as a result of the processes the product has had.

Compared to the building process, it is necessary to consider two levels of energy use associated with the process: the capital and the operating power. With regard to the capital, all aspects of construction are considered, involving the consumption of primary energy embodied in the process of materials and building components: extraction of raw materials, manufacturing process, transportation to the site, plus the energy required during the construction phase of the project itself. 
Capital consumption energy is an important item on the study of materials and efficient construction processes in terms of air emissions and transport in the urban metabolism. These determinants have environmental considerations, aimed at reducing the impacts of construction and the possibility of raising strategies of mitigation or compensation, which can be integrated as a factor for sustainable design [1].

The component of atmospheric emissions is approached from two perspectives: emissions with direct impact on air quality and public health at the local level, specifically generated in the construction phase and greenhouse gas (GHG) emissions, thereby contributing to the phenomenon of global climate change, produced throughout the life cycle of the construction project and materials.

\section{Contextual framework}

The urban growth in the metropolitan area of the Aburrá Valley relates directly with the increasing construction activity. Construction during the last two decades in the region presents a considerable increase in $\mathrm{m}^{2} /$ year from 2001, with higher levels than the 2.5 million $\mathrm{m}^{2} /$ year in 2013, distributed as total of housing built including new and reformed corresponds to 1.9 million $\mathrm{m}^{2} /$ year and the construction of buildings with other uses corresponds to $320,700 \mathrm{~m}^{2} /$ year [2].

With the analysis of the number of $\mathrm{m}^{2}$ built by the municipality for 2012 , for different types of projects, adds approximately 2,245.229 $\mathrm{m}^{2}$ in newly built area.

The building systems used in the metropolitan area of the Aburrá Valley are mainly: confined masonry in $77 \%$ of new construction, concrete walls or structural screens in $14.9 \%$ and structural masonry with $6.4 \%$. Although the construction sector is one of the largest industries in the region, many of the processes developed are handmade, far from being classified as industrialized. This is the case of the construction in the AMVA sector, where most of the projects are developed with traditional construction systems.

Each building system demands a different amount of materials for its composition. Figure 1 shows the three most widely used systems in the Metropolitan Area of the Aburrá Valley, where the conventional masonry materials consume twice as much as the other two building systems. The fact that a building system demands more material than another results in a greater impact on the exploitation of primary resources, consumes more energy and generates a greater amount of emissions; actions that increase the carbon footprint of the material and therefore, make less sustainable the construction system.

It is not easy to distinguish the specific pollutant emissions associated with construction in the metropolitan area of the Aburrá Valley, because the technical documentation analyzed doesn't allow the impact of construction, on air quality or the little importance given to these sources, due to the short periods of direct influence to be quantified in a timely manner:

- The manufacture of building materials reported as part of the manufacturing emission inventory. 
- The transport of materials to the building site and transport of construction and demolition waste to disposal sites, reported as part of the inventory of emissions from transport sector.

- The operation of machinery in work, even though it does not appear in reports.

2500

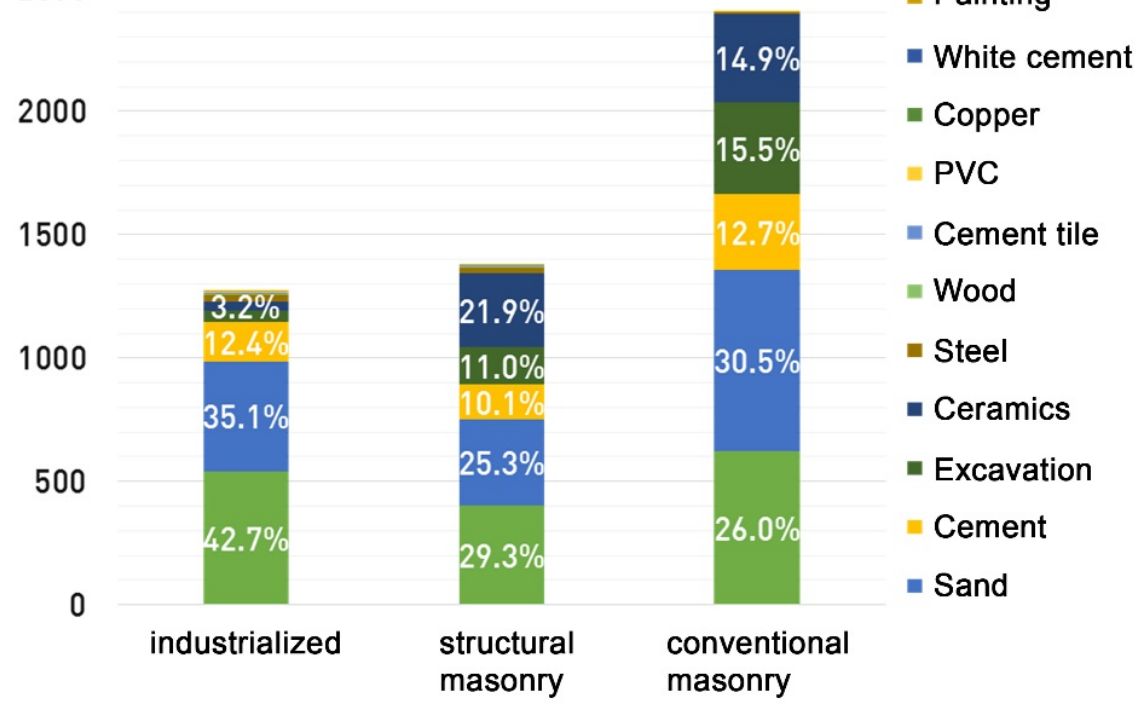

Figure 1: Consumption materials for building systems. Determination of physical and estimation of energy consumption in the production of steel, concrete, glass, brick and other materials used in the construction of buildings in Colombian (UPME, UNDP, ecoengineering, 2012) properties.

\section{Methodology}

During this research the methods of application of the emission factors of carbon footprint for building materials present in the Colombian industry were analyzed and studied, recently calculated by the Environmental Program of the United Nations and the Planning Unit Mining energy (UPME). Total emissions from the production of building materials used in building systems, adopted in projects in the metropolitan area of the Aburrá Valley, according to data issued by the industries that produce them, relating to $\mathrm{m}^{2}$ per year were calculated in each building systems.

Finally, strategies were established to achieve the reduction of emissions and the impact on the environment that generates the selection and use of the products or building materials in building systems. 


\section{Results}

\subsection{Quantification of $\mathrm{CO}_{2}$ emissions and GHG building materials.}

According to the record of Environmental Archive AMVA in the Aburrá Valley, over 300 companies are likely to generate discharges into the atmosphere. In the emissions inventory 2011, these industries were classified into 12 sectors according to their productive activity, however, for the study of this work, four sectors were considered, which, by their level of importance, had a direct relationship with the construction sector.

Table 1: Production activities associated with the construction sector in the Aburrá Valley. Adapted from air emissions inventory, Aburrá Valley, 2011.

\begin{tabular}{|c|l|}
\hline $\begin{array}{c}\text { Production } \\
\text { activity }\end{array}$ & Description \\
\hline CVL & $\begin{array}{l}\text { Ceramic and vitreous: brick, pottery, ceramic tile factories and } \\
\text { industries. }\end{array}$ \\
\hline MMC & $\begin{array}{l}\text { Metalworking: metal smelting and management, iron, } \\
\text { nonferrous metals, production of electrical machinery and non- } \\
\text { electrical. }\end{array}$ \\
\hline ASF & $\begin{array}{l}\text { Petroleum derivatives: production and asphalt and asphalt } \\
\text { emulsions, exploitation and processing of ground processing. }\end{array}$ \\
\hline MAD & Sawmills, lumber yards, and woodworking industries. \\
\hline
\end{tabular}

These four sectors associated with construction activity equal $30 \%$ of industries from Aburrá Valley and contribute 35\% of emission sources in the metropolitan area. The ceramic and vitreous industries are contributing the largest releases of pollutants and GHGs related to other productive sectors.

Table 2: Percentage distribution of data and criteria pollutant emissions by productive activity. Based on data from air emissions inventory, Aburrá Valley, 2011 base year.

\begin{tabular}{|l|c|c|c|c|c|c|c|}
\hline Sector & CO & Nox & Sox & VOC & PM & PM10 & PM2.5 \\
\hline CVL & 514.4 & 777 & 251.3 & 36.5 & 433 & 62.9 & 48.3 \\
\hline MMC & 231.2 & 46.2 & 61.3 & 9.8 & 50.4 & 28 & 12.3 \\
\hline ASF & 31.3 & 23.4 & 22.3 & 2.7 & 6.3 & 1.8 & 1.2 \\
\hline MAD & 7.3 & 2.7 & 0.3 & 0.5 & 6.7 & 6 & 5.2 \\
\hline Total & 784.2 & 849.3 & 335.2 & 49.5 & 496.4 & 98.7 & 67 \\
\hline
\end{tabular}


Referring to the total emissions from stationery sources, industries associated with construction contribute with $27 \%, 39 \%, 15 \%, 5 \%$ and $22 \%$ of emissions of $\mathrm{CO}, \mathrm{NOx}, \mathrm{SOx}, \mathrm{VOC}$ and PM2.5 respectively. Industry related to the production of building materials, has a low contribution to the direct GHG emissions within the Aburrá Valley, representing only $6 \%$ of GHG emissions in the metropolitan area.

Table 3: Distribution of emissions of GHGs by productive activity. Based on data from air emissions inventory, Aburrá Valley, 2011 base year.

\begin{tabular}{|l|c|c|c|}
\hline Sector & $\mathbf{C O}_{2}$ & $\mathbf{C H}_{\mathbf{4}}$ & $\mathbf{N}_{\mathbf{2}} \mathbf{O}$ \\
\hline $\mathrm{CVL}$ & 178.191 & 5 & 2 \\
\hline MMC & 30.245 & 3 & 1 \\
\hline ASF & 26.086 & 1 & 0 \\
\hline MAD & 2 & 0 & 0 \\
\hline Total & 234.524 & 10 & 3 \\
\hline Total CO -eq & \multicolumn{4}{|c|}{234.537} \\
\hline
\end{tabular}

However with a focus on life-cycle, the carbon footprint of building materials is high. The inventory of direct GHG emissions taken into account currently, has no emissions of extractive activities in general and also excludes emissions from manufacturing, related to the production of building materials, when it takes place outside the Aburrá Valley. But if the analysis of this aspect is done under a lifecycle approach, the contribution of construction materials to GHG emissions is very meaningful.

Applying these emission factors to data on $\mathrm{m}^{2}$ built, by type of system in the Aburrá Valley and intensity of materials by type of construction system nationally, you find the GHG emissions associated with the life cycle of construction materials, is up to $1,200,000$ ton $\mathrm{CO}_{2}$-eq/year.

\subsection{Mitigation systems to environmental impact of materials used in the construction processes in the Aburrá Valley}

\subsubsection{Selection criteria of materials}

Materials selection considering the physical properties of these, from bioclimatic parameters, allows the definition of satisfactory thermal, lighting and acoustic environments for users and avoids excessive use of artificial conditioning systems.

When speaking of materiality from a sustainability perspective, is necessary to consider the selection of the constituent materials of a project, with a global, comprehensive and awareness concept of their components and systems. For a material to be considered sustainable, it must meet four basic principles:

- Both the material and the constructive system of which it is part, must follow with the conditions and requirements set by the Colombian Technical 
Table 4: GHG emission factors of the construction materials used in Colombia (PNUD, UPME, Ecoingeniería (2012)).

\begin{tabular}{|l|c|}
\hline Material & $\mathrm{CO}_{2}$ emissions total (ton $\mathrm{CO}_{2} /$ ton) \\
\hline PVC & 7.659 \\
\hline Guadua & 0.107 \\
\hline Coarse aggregate & 0.01 \\
\hline Fine aggregate & 0.021 \\
\hline Base & 0.013 \\
\hline Sub-base & 0.011 \\
\hline Sand & 0.01 \\
\hline Brick & 0.243 \\
\hline Tiles & 0.83 \\
\hline Steel & 2.705 \\
\hline Copper & 8.622 \\
\hline Lime & 0.798 \\
\hline Wet cement & 1.185 \\
\hline Dry cement & 1.096 \\
\hline Chemical plaster stucco & 0.203 \\
\hline Plaster stucco & 0.205 \\
\hline Painting & 0.408 \\
\hline Wood & - \\
\hline Cement tile & 0.052 \\
\hline Glass & 1.859 \\
\hline Adding K-environmental & 0.125 \\
\hline Eco cement & 0.211 \\
\hline Ecological brick cement & 0.085 \\
\hline Ecological brick & 0.056 \\
\hline Recycled aggregates & 0.001 \\
\hline Aluminium & 1.6 \\
\hline & \\
\hline & \\
\hline
\end{tabular}

Standards (NTCs) and the Earthquake Resistance Standard NSR 10. Any materiality, or component which does not comply with the characteristics defined by these standards, jeopardize the safety and welfare of consumers, therefore are considered unsustainable.

- The material or construction system mentioned before, must be scalable, with the possibility of varying dimension depending upon the specific application required.

- The system must be replicable, to answer a model for standardization of the product, which can be standardized under its process. 
- Finally, even just one item that complies with the principles described above, but has low durability or needs to be replaced several times during the life of the building, the negative impact of this condition, puts into perspective the actual level of sustainability that has a materiality.

The products sold in the construction sector in Colombia do not have the obligation to publish their carbon footprint. However, the strategy of some companies to bring in product labels, the values of $\mathrm{CO}_{2}$ emitted in the manufacturing process give consumers the possibility to opt for materials that are guaranteed to be cleaner, with a production that generates lower impact on the environment.

\subsubsection{Modularization and prefabrication systems implemented in the design}

When speaking about modular design, it refers to the application of the concept of dimensional coordination and/or modular in the architectural design process. The dimensional coordination is the application of a range of measures for the design of components and assemblies incorporated in the building (Building and Construction Authority, Modular Coordination, Singapore). Modular coordination, on the other hand, is a dimensional coordination module which uses a basic unit of measurement, using this with its multiples and submultiples to develop the building and its various components [3].

The application of these concepts implies a close relationship between the manufacture of the components, the building design and construction phase, resulting in multiple practical benefits and efficient multi-project cost, also "practical benefits and systematic implementation and achievement of this technique ensures optimum stage of construction, faster and cheaper assembly of items of different origin, function and features" [4].

Thus the decrease in the generation of RCDs, enables the reduction in the time of project implementation, due to increased efficiency in installation and optimization of resources, while reducing the costs of the project. This condition makes the modular design an effective strategy that will contribute greatly to the project's sustainability.

\subsubsection{Designing for deconstruction}

Deconstruct refers to the task of gradual disassemble or removing a building, in order to recover its components, partly or wholly, to be reused or recycled. This activity reduces the amount of waste that must be disposed of in dumps.

Although rare in the local environment, it is not a new concept. Before the existence of heavy machinery, deconstruction was the means by which the buildings were disassembled in most of the world [5]. This strategy is implemented partially and unconsciously in some cases, when construction elements are recovered, before starting a process of demolition.

From an environmental perspective, one of the main benefits of this activity is to close the loop of the linear use of resources to reduce dependence on new materials and reduce waste disposal in the dumps. In the Aburrá Valley there is over 8000 tons of RCDs [6], deconstruction is presented as an effective strategy to reduce the environmental impacts associated with the disposal of these. 
Designed to deconstruct implies a clear understanding of the close relationship that should exist between the architectural design and the process by which elements designed are materialized. Its aim is to define the assembly of a building at the end of its useful life, it can be dismantled, keeping the physical integrity of its components so that they are subsequently reused.

The design principles to deconstruct facilitate removal and replacement of building components, which gives this greater flexibility and adaptability to possible changes in its function throughout life, a condition that could even be extended. In the same way, change processes are facilitated and prevent repair and maintenance processes in networks, resulting in extensive damage to more investment.

\section{Conclusions}

Given the conditions of population growth and urban development in the metropolitan area of the Aburrá Valley, it is necessary to consider systems and processes for measuring the environmental impacts and air emissions caused by construction and the manufacture or processing of elements and materials used in building systems.

But despite the limited information and analysis of updated data, for precise quantification of the environmental impacts of construction activity in the AMVA, it is possible to consider, from the relationship of existing data described in this work, a potential pollutant emission reduction to atmosphere from the sustainable materiality, higher and more profitable than the implementation of strategies for energy efficiency in buildings.

The scope of this potential emission reduction also supports the implementation of strategies and more complete construction design involving contributions to the energy efficiency of buildings.

Thus, the management and policy development of the country in terms of sustainable construction, should raise the materiality of buildings as a life cycle strategy of equal or higher priority than the current energy efficiency strategies.

\section{References}

[1] Szokolay, Steven. Inaugural Conference. In: 14th International Conference on Passive and Low Energy Architecture (17: 8 January 1997: Kushiro, Japan) Editors PLEA, 1997.

[2] Statistical Yearbook of Antioquia (Antioquia Government, 2012) and Municipal Records (AMVA, 2010-2008).

[3] 2000CIB and the International Modular Group, "The Principles of Modular Co-ordination in Buildings," Dublin, 1984.

[4] ICONTEC, "La NTC 45. Civil Engineering and Architecture. Modular construction coordination. Bases, definitions and general conditions." Bogotá, 1981. 
32 Eco-Architecture VI: Harmonisation between Architecture and Nature

[5] Livingston, D. and Jackson, M. "Building a Deconstruction Company. A training manual for facilitators and entrepreneurs." Institute for Local SelfReliance, Washington, DC, 2001.

[6] AMVA and UPB, "Technical Support Document for the Development of Public Policy for Sustainable Construction for the Metropolitan Area of the Aburrá Valley," Medellín, 2015. 